\title{
Aproximación epistemológica a los imaginarios sociales, como categoría analítica en las ciencias sociales
}

\author{
Epistemological Approach to Social Imaginaries, \\ as an Analytical Category within Social Science \\ Claudia María García-Muñozi (iD) 을 \\ Rafael Ángel Gómez-Gallegoii (i) (-) \\ ${ }^{i}$ Facultad de Derecho, Ciencias Politicas y Sociales; Universidad Libre de Pereira; Pereira; Colombia.

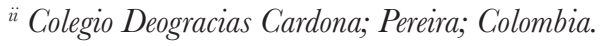

Correspondencia: Claudia María García Muñoz. Correo electrónico: claudiam. garciam@unilibre.edu.co

Recibido: 04/07/2020

Revisado: 21/05/2021

Aceptado: 08/06/2021

Investigación. Este artículo es producto de la revisión epistemológica llevada a cabo en el marco de la tesis doctoral Significaciones imaginarias en torno a la ciudadania y la religiosidad, en un grupo de jóvenes universitarios de Pereira, de autoría de Rafael A. Gómez, con la tutoría de Claudia García M., la cual se encuentra actualmente en marcha en el programa de doctorado en Ciencias Sociales Niñez y Juventud, de la Universidad de Manizales, en convenio con CINDE-Manizales.

Citar así: García-Muñoz, Claudia María; Gómez-Gallego, Rafael Ángel. (2021). Aproximación epistemológica a los imaginarios sociales, como categoría analítica en las ciencias sociales. Revista Guillermo de Ockham, 19(2), pp. 219-232. https://doi.org/10.21500/22563202.4807

Copyright: () 2021. Universidad de San Buenaventura, Cali. La Revista Guillermo de Ockham proporciona acceso abierto a todo su contenido bajo los términos de la licencia Creative Commons AttributionNonCommercial-NoDerivatives 4.0 International (CC BY-NC-ND 4.0)

Conflicto de intereses. Los autores han declarado que no hay conflicto de intereses.

Disponibilidad de datos. Todos los datos relevantes están en el artículo. Para

\section{Resumen}

Este artículo tiene como intención proponer una reflexión epistemológica sobre los imaginarios como categoría analítica en las ciencias sociales, mediante la cual se pueden comprender los múltiples sentidos que configuran los sujetos en su interacción en torno a diferentes aspectos de su vida social, tales como la ciudadanía y la religiosidad. Así mismo, las reflexiones aquí propuestas forman parte del proceso investigativo adelantado en la tesis doctoral en marcha titulada Significaciones imaginarias en torno a la ciudadania y la religiosidad, en un grupo de jóvenes universitarios de Pereira. Como parte de la fundamentación epistémica y teórica de dicha categoría, se ha llevado a cabo una revisión amplia de su uso en las ciencias sociales, especialmente según la teoría social de Castoriadis y otros autores afines, cuya línea de reflexión común busca dar cuenta de los sentidos en la vida particular. En este orden de ideas, se hicieron revisiones teóricas e investigaciones relacionadas en las cuales se muestra que dicha categoría, atravesada por la cultura, se convierte en un recurso analítico potente desde donde es posible aprehender los sentidos generados por la interacción social y a su vez, develar la forma como operan dichos sentidos, dando sustento así a las prácticas sociales relacionadas con las tramas construidas entre ciudadanía y la religiosidad. En suma, los imaginarios constituyen una categoría bisagra a través de la cual se logra identificar la relación entre el actor y el mundo y a partir de ello la construcción de sus realidades.

Palabras clave: imaginarios sociales, epistemología, ciudadanía, religiosidad

\section{Abstract}

This article is designed to put forward an epistemological reflection on imaginaries, as an analytical category in social science, through which the multiple meanings that subjects make up in their interaction, around different aspects of their social life, such as citizenship and religiosity. Likewise, the reflections put forward herein are part of the research process conducted in the ongoing doctoral dissertation entitled "Imaginary Meanings around Citizenship and Religiosity, in a Group of Young University Students from Pereira." As part of the epistemic and theoretical foundation of this category, a broad review of its use in social 
mayor información contactar al autor de correspondencia.

Fondos. Ninguno. Esta investigación no recibió ninguna subvención específica de agencias de financiamiento de los sectores público, comercial o sin fines de lucro.

Descargo de responsabilidad. El contenido de este artículo es responsabilidad exclusiva de los autores y no representa una opinión oficial de sus instituciones ni de la Revista Guillermo de Ockham. science has been conducted, especially as per the social theory of Castoriadis and other related authors, whose common line of reflection aims to account for private-life senses. Accordingly, theoretical reviews and related research were carried out, which shown that this category, permeated by culture, becomes a powerful analytical resource that enables a comprehension of the meanings created by social interaction while revealing the way in which such meanings work, thereby providing support to social practices related to the plots built between citizenship and religiosity. In short, imaginaries are a hinge category that makes it possible to identify the relationship between the actor and the world and, based on this, the construction of their realities.

Keywords: social imaginaries, epistemology, citizenship, religiosity

\section{Introducción}

Comprender los sentidos que configuran los sujetos en torno a diferentes aspectos de la vida social, es una tarea que exige al investigador no solo reconocer los fundamentos teóricos desde los cuales se conceptualiza su objeto de estudio, sino también buscar formas de acercamiento apropiadas para aprehender dicho objeto. Con base en la revisión teórica llevada a cabo a partir de la investigación titulada Imaginarios en torno a la ciudadanía y la religiosidad, en un grupo de jóvenes universitarios de Pereira, se plantean los aportes epistemológicos más relevantes en torno a la categoría "imaginarios" para derivar una reflexión sobre su contribución como categoría analítica, desde la cual es posible comprender el sentido que construyen los sujetos en torno a diferentes aspectos de su vida social. En este orden de ideas, interesa abordar por qué los imaginarios se pueden asumir como mediadores en la comprensión de los sentidos sociales; es decir, por qué dicha categoría se constituye como traductora de la realidad mediante el ejercicio hermenéutico, convirtiéndose de esta manera en un dispositivo metodológico relevante en el campo de las ciencias sociales. Así, se pretende transitar de la teorización sobre el objeto en sí mismo hacia su utilidad epistémica para la comprensión de la realidad.

Con la intención de abordar los aportes epistemológicos sobre los imaginarios como categoría analítica mediadora de la comprensión de sentidos respecto a aspectos de la vida social, interesa, en este artículo, enfatizar dicha reflexión sobre la relación entre la ciudadanía como estatus de actuación político-social de los sujetos y la religiosidad como disposición subjetiva de estos. En ambas dimensiones, a saber, la práctica y la disposición subjetiva, se plantea, a modo de tesis, que la configuración de sentidos surgida de esta relación se genera en el proceso interdependiente de producción de imaginarios que determinan dichos sentidos.

Para Castoriadis (1989), los imaginarios determinan las prácticas del sujeto político y del anónimo social, ampliando así su incidencia en todas las dimensiones de la existencia social. Sin embargo, en el presente artículo interesa, particularmente, interrogar las formas como los jóvenes configuran imaginarios que dotan de sentido la relación entre su ciudadanía y su religiosidad. En virtud de lo anterior, concierne encontrar los fundamentos epistemológicos de esta relación, pues en la intersección entre ambas dimensiones -la praxis y la disposición subjetiva- se presume la configuración de sentidos dada mediante un proceso autopoiético de producción de imaginarios.

El interés por profundizar en la categoría de imaginarios sociales como mediadores de conocimiento social, implica abordarla como constructo explicativo de los fenómenos sociales y también como herramienta hermenéutica para interpretar los sentidos que los sujetos experiencian. En este orden de ideas, se abordan inicialmente los antecedentes teóricos de los imaginarios sociales. Seguidamente, se hace un breve acercamiento a la 
teoría de los imaginarios a partir de los postulados de Castoriadis (2004) y finalmente, se propone una aproximación a un estado del arte con la intención de rastrear los procesos investigativos que han utilizado los imaginarios sociales como categoría mediadora en el campo de las ciencias sociales, para aprehender los sentidos de los sujetos políticos.

\section{Algunos antecedentes y referentes teóricos en torno a la categoría imaginarios}

En hebreo antiguo, la palabra imagen viene de la raíz (tzelem) que significa o se relaciona con "sombra". לִ (tzel). Una sombra es una imagen imperfecta que se asemeja a la cosa real que proyecta. En la tradición judeocristiana, Tzelem Elohim, significa la "imagen de Dios" que puede ser entendida como la sombra de Dios, en el sentido de que es una copia imperfecta de la imagen real perfecta (Miranda, 2008). También da el sentido de una imagen que tiene el potencial para ser semejante a su divinidad. En la afirmación de este concepto, el texto de la Torá del génesis, contiene la siguiente sentencia: "Y Dios creo al hombre a su imagen y semejanza", y en ella se extiende el sentido a autonomía y poder para gobernar.

Para los griegos, el concepto “imagen” -en griego \&ıкóva (eikóna) - significa "parecido o igual", lo cual implica que la imagen puede sustituir en algún momento, al objeto mismo (Tuggy, 2003). Platón recurre a una distinción entre conocimiento verdadero -eikón-y falso - eidolon-y así mismo, ubica las imágenes en función de la correspondencia con un tipo de conocimiento, aunque hace énfasis en que las imágenes están relacionadas con lo apariencial, la imagen fantasmal o sombra de los muertos. Desde esta perspectiva, su pensamiento entra en tensión con los sofistas, quienes creían que la imagen es lo que es, aunque puedan existir imágenes engañosas. Así mismo, Aristóteles en la noética -doctrina del conocimiento- sostenía que era imposible pensar sin fantasmas, refiriéndose a las imágenes.

Al hilo de lo anterior, en el recorrido histórico del desarrollo del concepto imagen, Agustín de Hipona sostendría, en la Edad Media, que las ideas son imágenes divinas, apoyándose en la teoría de Platón sobre los dos mundos (Argüello, 2012). De la misma manera, Tomás de Aquino, influenciado por Aristóteles, afirmaría que las imágenes son las percepciones del mundo y de la belleza relacionadas con el bien. Por ello, la imagen constituía un signo inmaterial, reflejo de la presencia divina y se convertía en la llamada "estética de la luz" punto de partida para todo conocimiento, a partir del cual era posible significar las esencias de las cosas:

Para Tomás, la habilidad de expresar proposiciones está estrechamente relacionada con el conocimiento de las esencias, ya que para este proceso es indispensable recurrir a las imágenes mentales, los phantasmata, de los cuales el intelecto agente abstrae aquello que se conoce, es decir, las esencias. (Tellkamp, 1996, p. 48)

En la Edad Moderna, Emanuel Kant plantea que la imaginación es el enlace entre lo sensible y el entendimiento. Por tanto, la imaginación formada por imágenes es necesaria como a priori del mundo y a la vez como conocimiento sobre él. En consecuencia, las imágenes son representaciones previas que dan pie a la síntesis figurativa de las percepciones de donde se forman los conceptos sobre la realidad.

En el siglo XX, el filósofo Castoriadis (1989), propone su teoría de la imaginación radical, en la que atribuye a dicha imaginación todo el poder generativo y transformador de la realidad social. Para este filósofo, la imagen es potencia generativa desde la cual emerge lo nuevo y la transformación, en un contexto histórico determinado. Ahora bien, 
imagen e imaginación son derivas que exigen una delimitación conceptual. Al respecto, Cegarra (2012), sostiene que estas nociones son

(...) términos que difieren entre sí, a pesar de su proximidad etimológica. Puede resumirse que la imaginación es una capacidad individual, que parte de la realidad social para imitarla o recrearla, y que remite al uso de imágenes como vehículos de su manifestación y está socialmente reconocida. Su primordial diferencia con el imaginario social es que éste no es una facultad humana, en tanto proceso cognitivo y emocional. El imaginario social constituye una "gramática", un esquema referencial para interpretar la realidad socialmente legitimada, construido intersubjetiva e históricamente determinado. La imaginación es representativa, el imaginario interpretativo. En conclusión, la diferencia fundamental entre una y otro estriba en que la imaginación es una innata facultad humana y el imaginario social, una condición o regulación externa como característica propia de la vida en sociedad. (p. 4)

En las últimas décadas han surgido diversas teorizaciones acerca de la imaginación. Entre otras, se tiene el aporte de Zolla (1968), para quien se trata de juicios subjetivos. Para Ugas (2007), la imaginación es una actividad mental que se expresa a través de imágenes, las cuales representan contenidos de conciencia. Para Ferrater Mora (1992), la imaginación es un estado de producción y reproducción de imágenes. Simón (2002), plantea que se trata de una capacidad mediante la cual es posible reproducir copias de los originales una vez percibidos, clasificándolos en reproductivos y productivos.

Estas nociones de la imaginación se hacen extensivas al concepto de imaginario, cuya naturaleza es análoga a la imaginación en cuanto imagen, pero conlleva elementos diferenciadores en su proceso de configuración, su estructura y contenido, que lo definen como una locución adjetiva de lo social y no como un proceso psíquico. En los últimos tiempos, esta noción ha sido ampliamente utilizada y se ha creado una suerte de traslapes e indefiniciones producto de un uso excesivo, ligero e irreflexivo del término, que empieza a ser usado como comodín de todo tipo de análisis cultural (Reynoso, 2000).

Pese a la complejidad de estas nociones, es posible establecer una demarcación conceptual, al menos como una distinción entre imaginación como proceso psíquico desde el cual es posible generar algo que no ha sido, que no es y no está, valiéndose de imágenes recreadas de lo existente, e imaginario social, que adjudica una cualidad a dichas imágenes mediante una "gramática de simbolizaciones" para interpretar la realidad, la cual puede estar legitimada e instituida o puede ser generativa e instituyente. En suma, el imaginario social contiene tanto la representación de la imaginación como su interpretación, de acuerdo con el contexto histórico-cultural en el que se produce la realidad social. En suma, el imaginario se define como "la inevitable representación, la facultad de simbolización de la cual emergen continuamente todos los miedos, todas las esperanzas y sus frutos culturales desde hace aproximadamente un millón y medio de años, cuando el homo erecto se levantó sobre la tierra" (Durand, 1992, p. 77).

Para Baeza (2008), el imaginario social es un locus de sentido, instituido hegemónicamente e impuesto al sujeto como metarrelato de la vida. Claro está que los imaginarios se transforman a la par que las condiciones sociales, razón por la cual existen imaginarios instituidos e instituyentes, lo que representa la lucha constante de imposición de una visión hegemónica del mundo para hacerla parecer natural, frente a un movimiento emergente e instituyente de la realidad. Según este autor, los imaginarios sociales matizan respuestas a enigmas de la vida social con afirmaciones fuertes tales como la presencia de Dios. Por ello, para Baeza (Ibíd.), la función de los imaginarios sociales es la construcción convincente de la realidad, ejerciendo así una mediación entre la realidad y nuestra percepción de ella.

Otro pensador que aporta a la comprensión de los imaginarios es Charles Taylor (2006), quien plantea que los imaginarios sociales son aquellos reservorios de sentido 
para las prácticas sociales. Así las cosas, son más que imágenes o ideas y motivan la acción social de una manera coherente. Este autor identifica tres fases en el proceso por el cual una idea o conjunto de ideas logra convertirse en imaginario o alterar los ya existentes:

1. La emergencia en un contexto especializado, referido a las reflexiones y conocimientos ofrecidos por los filósofos y los teóricos de las leyes

2. El paso de un contexto especializado a un contexto no especializado; es decir, lo especializado se traduce a un lenguaje y un conocimiento común.

3. El tránsito de lo hermenéutico a lo prescriptivo, que señala el movimiento desde una explicación hacia una materialización del discurso.

De otra parte, Pintos (2005), aporta otras conceptualizaciones sobre los imaginarios y su posicionamiento como una categoría social explicativa. Para dicho autor, los imaginarios representan esquemas de la realidad construidos socialmente, mediante los cuales es posible percibir lo exterior como real, explicarlo e intervenir operativamente en lo que en cada sistema social se considere como realidad. Así, los imaginarios contienen la realidad y tienen la fuerza suficiente para regular los comportamientos sociales.

Tanto, Taylor (2006) como Pintos (1995), Baeza (2008), Abric (2001) y Carretero (2001), resaltan el poder de los imaginarios como categoría heredera del racionalismo, pues portan los sentidos que configuran los sujetos y son encarnados en instituciones societales como la familia, la educación, los medios de comunicación, el Estado y la Iglesia, entre otras.

En este entramado conceptual, el símbolo y la imaginación son significantes de un significado condensado en lo imaginario. Tales explicaciones han sido rechazadas por la tradición positivista del conocimiento científico. A pesar de la prevalencia de este paradigma en la ciencia, actualmente se han elaborado nuevas discusiones teóricas que señalan estos reduccionismos al estudiar la realidad social, dando así cabida a nociones como la imaginación, que ha operado en campos como la literatura, pero ahora se extiende a las ciencias sociales, mostrando de esta manera que es a partir de este locus de comprensión que es posible descubrir lo insacrificable de la vida particular y por tanto de la buena política. En suma, los imaginarios no solo actúan como filtros invisibles que van prefigurando la vida particular, sino que, además, se convierten en una herramienta para comprenderla (Osorio, 2017).

Tal como se ha venido sosteniendo, los imaginarios son tanto la expresión condensada de los sentidos del colectivo anónimo como de los sentidos legitimados a través de las instituciones sociales. Inicialmente, dichos imaginarios son instituyentes en cuanto de fuerza creadora emergen las instituciones sociales que responden a un contexto histórico determinado, para, posteriormente, ser absorbidos socialmente para operar como marcos interpretativos de la realidad, convirtiéndose así en imaginarios instituidos. Es decir, validados, legitimados socialmente y materializados mediante prácticas discursivas, opiniones, actitudes valores y normas que circulan en el orden simbólico, las cuales, a su vez, se constituyen condicionantes de la creación siguiente. De esta manera, los imaginarios operan en un continuo movimiento en dos planos: en el colectivo anónimo para generar cohesión social, y en el sujeto individualizado, como reservorio de sentido para la configuración de subjetividades (Castoriadis, 1998, 2004). Estos imaginarios sociales regulan dentro de un orden establecido, tanto al sujeto como a los colectivos, otorgando de esta manera sentido a la acción social dentro de dicho orden y con ello consolidando una determinada realidad. 
En esta breve reseña teórica sobre los imaginarios, insuficiente para dar cuenta de su multidimensionalidad, pero útil para evidenciar el papel que como categoría analítica tienen en la comprensión de la realidad social y del sujeto dentro de ella, se infiere que dicha categoría cumple más que una función descriptiva, pues su potencia epistemológica recae en sus posibilidades como "mediación analítica" que, de un lado, traduce los fenómenos ocurridos en el mundo social y los reviste de imágenes significadas, y de otro, libera la potencia creadora de la imaginación radical depositada en el magma social que moviliza energías y flujos, a partir de los cuales se producen nuevas realidades en el orden instituyente que pugnan por encontrar un posicionamiento en el orden instituido de la sociedad. Con base en esta reflexión y en consonancia específica con el interés investigativo que anima este artículo, se puede inferir que a partir de la identificación de las imaginarios presentes en un grupo de jóvenes universitarios en torno a su ciudadanía y su religiosidad, es posible aprehender la forma como están construyendo estas realidades y el sentido que dichos jóvenes les atribuyen a estas dos dimensiones de su existencia, constituyendo así una importante herramienta analítica para reconocer las prolongaciones, las transiciones y los desplazamientos instituyentes que contribuyen a la transformación de lo existente y la generación de nuevos ordenes instituidos.

\section{El imaginario social como categoría ontopolítica}

Toda posibilidad de aprehender la existencia ontológica de una realidad social implica dar cuenta de su origen como producción de lo sensible y de lo simbólico. En virtud de ello, los imaginarios sociales constituyen la mediación de estos dos registros. En este sentido, la dimensión política representada en el proyecto de autonomía (Castoriadis, 1989), es simbolizada a través de la participación en la construcción de órdenes normativos, mediante las prácticas de ciudadanía. Es así que dicho autor plantea que la conquista del proyecto de autonomía consiste en el despliegue de la resistencia frente a las estructuras políticas y sociales imperantes, sustentadas en valores anacrónicos, lo cual da paso a la imaginación de mejores instituciones que los humanos pueden darse. Este proceso deviene en proyecto histórico y político, en cuanto constituye conocimiento social derivado de la relación entre sujetos, política e imaginación, de donde emergen los imaginarios instituyentes nacidas de las prácticas ciudadanas; es decir, la praxis social moviliza el magma hacia la creación.

En esta ontopolítica, el papel del lenguaje será el de performar las prácticas instituyentes a partir de los magmas simbólicos que alientan y estimulan la acción humana. Así lo afirma Castoriadis (1989):

Lo imaginario del que hablo no es imagen de. Es creación incesante y especialmente indeterminada (histórico-social y psíquica) de figuras/formas/imágenes, a partir de las cuales solamente puede tratarse de "alguna cosa". Lo que llamamos "realidad" y "racionalidad" son obras de ello. (p. 12)

El reconocimiento de estas cuestiones epistémicas deviene, a su vez, en el reconocimiento de una pluralidad metodológica y multidisciplinar. Ante esta necesidad, urge que el discurso sobre lo social escuche con más atención la vida de lo particular imbricada en lo instituyente, aunque este lenguaje traído de las artes y de la literatura, pueda molestar a las inteligencias rigurosas formadas en el racionalismo del siglo de las luces: "El rigor excesivo se aleja de lo real y la advertencia de Leibniz tiene actualidad para el sociólogo: cuidado con los engańos de la lógica, que ciegan ante la labilidad de las cosas, ante su avance dificultoso" (Maffesoli, 1993, p. 52). 
La teoría de los imaginarios conlleva una manera diferente de comprender la historia. Así lo afirma Castoriadis (2004): "Comprender los fenómenos sociales contemporáneos desde el horizonte de la teoría de los imaginarios, es reconocer que la humanidad es la historia del imaginario humano y de sus obras." (p. 121). La imaginación no cumple una función imitativa o reproductiva, ni lo imaginario consiste en una instancia especular, sino que corresponde a la potencia creadora de formas y figuras nuevas tanto en el plano de la psique como en el de la sociedad, cuya tensión se expresa a través del conflicto psíquico, en lo que Uribarri (2000) denominó una sublimación extendida.

El imaginario se hace visible cuando se quiere hablar de algo "inventado" -ya se trate de un "invento absoluto" o de un deslizamiento o desplazamiento de sentido- en el que unos símbolos ya disponibles están investidos con otras significaciones que las suyas "normales o canónicas". Lo imaginario es creación radical, que mediante complejos procesos de aceptación y legitimación, adquieren el carácter de sociales en cuanto elementos coadyuvantes de la cohesión social del colectivo anónimo (Castoriadis, 1989). Esta relación imaginario/sociedad, resulta constituyente de la vida política de los individuos y los habilita para participar en la construcción de sus instituciones y de sus leyes.

En consecuencia, este autor propone una teoría de la creación social a partir de la articulación de algunas nociones centrales acopladas a los imaginarios sociales. En primer lugar, habla del magma de imaginarios como una multiplicidad de la que resulta imposible numerar los elementos que la conforman, sustrayéndose de la antinomia que el pensamiento heredado le asignó respecto a la categoría de lo uno. No es un caos desordenado que se oponga a la lógica conjuntista identitaria, sino un reservorio del que es posible extraer conjuntos de manera indefinida, sin por ello agotar sus remisiones ni tampoco ser posible de reconstitución por composición conjuntista. Un tejido embrollado, al decir del autor, de particularidades que la lógica de conjuntos recorta, actualiza y organiza, soportando aún su carácter de fuente inagotable de futuras actualizaciones. El magma es la fuente de alteración incesante, es decir, del tiempo imaginario en cuanto creación constante de nuevas significaciones. Por lo tanto, los imaginarios son categorías que dan forma a lo inventado, a lo producido desde el magma de creación.

En segundo lugar, aparece el imaginario radical, el cual se define como la capacidad de la psique de crear un flujo constante de representación, deseo y afectos (Castoriadis, 1997). El imaginario radical, es un poder hacer ser, a partir de imágenes de lo que no es, ni lo fue; una relación entre lo histórico-social y lo psicológico, desde cuyo topos emerge lo instituyente como posición, creación, posibilidad de ser.

En tercer lugar, hablamos de los imaginarios sociales instituidos, de cuya naturaleza solo es posible conocer sus manifestaciones, efectos y productos. Por lo tanto, el orden instituido no se puede aprehender, pero se acepta. El surgimiento de flujos de representaciones, con sus rupturas y discontinuidades (consientes e inconscientes), transforman o deforman las masas y energías en cualidades incorporadas en el orden simbólico, una suerte de normatización que convierte las significaciones en instituidas y "permiten a los individuos actuar socialmente, crear y ser compatibles con cierta cultura, de ellas se producen sentimientos y afectos que hacen relativamente armónicos a los sujetos" (Paya, 2005, p. 109).

La teoría del imaginario social no se agota con este breve abordaje, pero será, al menos, una aproximación para comprender sus herencias, su devenir, su contexto y cómo esto construye y trasforma las realidades sociales. Específicamente para nuestro objeto de estudio, interesa comprender cómo un grupo de sujetos jóvenes interiorizan estos 
imaginarios en torno a la ciudadanía y la religiosidad y cómo desde esta urdimbre, dichos jóvenes las reconfiguran y transforman.

\section{Imaginarios de ciudadanía y religiosidad: polifonía de sentidos}

Para utilizar la potencia descriptiva e interpretativa que acompańa el uso de los imaginarios en la relación entre ciudadanía y religiosidad, es necesario proponer una breve ubicación conceptual sobre estas categorías a partir de los aportes de pensadores como Rubio Carracedo, (2007), Hannah Arendt (2001) y Piedmont (2013).

En cuanto a la categoría ciudadanía, Carracedo (2007), propone un recorrido histórico que muestra la evolución de la noción de ciudadanía desde Atenas hasta nuestros tiempos, analizando algunas de las propuestas más relevantes, entre estas la de Marshall, quien asume la ciudadanía como normativa de identidad compartida entre individuo y Estado y la diferencia de una ciudadanía atada al pensamiento liberal, el cual enfatiza el estatuto legal del individuo frente al Estado. A cambio, esta ciudadanía republicana proclama la participación directa del individuo en la política, basada en una visión colectiva. Para el año 1954 -continúa analizando Carracedo-, aparece una noción de ciudadanía diferenciada basada en un pluralismo crítico que reconoce la necesidad de dar poder a los grupos minoritarios para alcanzar una ciudanía integral. A partir de estos elementos, el autor propone su teoría critica de la ciudadanía en la cual plantea tres principios fundamentales, a saber: 1 . la igualdad de derechos fundamentales para todo ciudadano; 2 . los derechos diferenciales para todos los grupos, y 3. las condiciones mínimas de igualdad dialéctica o dialogo libre y abierto entre los grupos socioculturales, lo que implica la formulación de políticas multiculturales.

De otra parte, Hannah Arendt (2001), propone un acercamiento multidimensional a la ciudadanía desde los conceptos de labor, trabajo y acción. Los dos primeros operan en el mundo privado y el tercero tiene una dimensión en lo público donde emerge el ciudadano que participa activamente en la política. Para esta filósofa, la ciudadanía se despliega cuando se está en la esfera de lo público, donde sea posible expresarse libremente, debatir, argumentar y estar en desacuerdo. La política es la posibilidad de crear nuevos órdenes mediante la acción y el discurso. Es así como debe pensarse en una ciudadanía emancipada de las determinaciones, de los condicionamientos diferenciales, de las identidades particularistas, para situar al ciudadano como

(...) actor principal de la emancipación política, pensado como un sujeto libertario, desobediente, crítico con su entorno, que recupera la capacidad de pensar por sí mismo y la posibilidad de gobernarse y gobernar, pues es él quien decide con otros qué sería más conveniente y apropiado para construir la vida en común. (Uribe, 2013, p. 178)

En consecuencia, para Arendt el sujeto político hace uso de su libertad política para crear lo que no existe y con ello actuar en el mundo. Ser libre y actuar es consustancial al sujeto político. En un sentido similar, Habermas (en Lozano, M., 2009) plantea que "el ciudadano debe ser un hombre que participa activamente en los asuntos humanos, copartícipe de la organización de la vida en la ciudad; hombres que tienen la experiencia de la libertad política”. (p. 103)

Por lo tanto, de los aportes teóricos de Carracedo y Arendt, podemos concluir que la ciudadanía es consustancial a la política y este no es posible sin un ciudadano como actor central de ella, más allá del Estado y de toda institución creada. La ciudadanía plena es, por tanto, universal, posnacional, sustrato de igualdad en cuanto acto político que contiene poder jurídico y constituye al sujeto libre, titular de derechos. Esta ciudadanía 
también es constitutiva de la acción que posibilita el tránsito de los derechos naturales a los derechos políticos; de la autonomía del juicio al discurso intersubjetivo; de la acción individual a la acción colectiva emancipada. En suma, se trata de una ciudadanía fundada en universales con mínimos irrenunciables, con derechos diferenciados y condiciones de igualdad para el disenso y el diálogo libre entre grupos socioculturales.

En cuanto a la religiosidad, retomamos los aportes de Piedmont (2013), no sin antes recordar las palabras de Durkheim (1964), cuando afirmaba que las cosas sagradas son aquellas que están protegidas y aisladas de lo profano mediante la prohibición. Así, las creencias y las prácticas asociadas a lo sagrado están diferenciadas del mundo profano, solo porque sobre ellas recae un sentido de lo inaccesible, el discurso simbolizado de lo vedado en la vida cotidiana. Por esta razón, para comprender la religiosidad en una cultura es necesario conocer los ritos de lo sagrado, la motivación de estos y la función que cumplen en la comunidad.

De otra parte, Marx Weber (1964), vincula lo religioso con el mundo social y encuentra en dicha relación convergencias y tensiones. En síntesis, la religiosidad en Weber se traducirá en la noción del culto, en la formación de una conducta religiosa motivada por los profetas o sacerdotes y en la esperanza de una salvación puesta al servicio de fortalecer una ética racional, que se expresa en la cultura de la obra social y el autoperfeccionamiento.

La religiosidad es una cualidad que, al menos, incluye diversas realidades. Al respecto, Calderon (en: Caerols, J., 2013, ed.) plantea que dichas realidades pueden clasificarse en dos grandes grupos: las personas y los sistemas culturales. En las personas, nos referimos a las actitudes, las experiencias, las acciones referidas a las prácticas religiosas, los grupos sociales tales como la congregación y los atributos personales como la motivación. En los sistemas culturales, se encuentran la cultura material, como la iconografía, y la cultura inmaterial que se refiere al lenguaje, las creencias y las normas. Para este autor, todas estas realidades que aluden al hecho religioso y portan la cualidad de religiosidad, tienen como elemento común "la referencia afirmativa sistémica a la existencia de alguna realidad divina” (p. 368). Dicha referencia puede darse en el mundo de la vida, de manera directa o estar implícita. En todo caso, siempre se tratará de una realidad trascendente que se manifiesta, de alguna manera, en la inmanencia del mundo, relacionada con la satisfacción de deseos humanos y que posibilita dicha satisfacción si el individuo se ajusta a esa realidad en su marco normativo. El autor también aclara que no es posible que exista una persona religiosa sin un sistema de significados religiosos desde el cual interprete la realidad, y tampoco puede existir dicho sistema sin estar encarnado en un individuo. Aunque esta relación se da en simultaneidad, lo cierto es que en la sociedad los sistemas de significados religiosos son precedentes a los individuos y por tanto se convierten en bancos de sentidos disponibles para los integrantes de una comunidad, dentro de su proceso de socialización. Sin embargo, este proceso de religiosidad es explicado desde una perspectiva construccionista, pues tal como el autor afirma:

La realidad fundamental es la física, en la que emergen los procesos psíquicos, de los que proceden las realidades ideales que constituyen el orden de los significados. Así, por ejemplo, un templo es una realidad religiosa por estar investida de significado por un sistema cultural religioso, que no existe nunca al margen de las personas religiosas que lo "portan". Lo fundamental es la religiosidad del sistema personal. (p. 370)

En suma, el fenómeno religioso no existe por sí solo, sino adjudicado a la religiosidad del individuo.

Por su parte, Piedmont (2013), provee herramientas para dar cuenta de la religiosidad al proponer la teoría de los cinco factores. Los postulados de dicha teoría se centran en 
los siguientes aspectos: 1 . tendencias básicas; 2 . características adaptativas; 3. biografía objetiva; 4. autoconcepto; 5 . influencias externas, y 6. proceso dinámico. En cuanto a las tendencias básicas, estas son de carácter psicobiológico, tales como la extraversión, la apertura a la experiencia, la amabilidad, la afabilidad o tendencia al acuerdo, la responsabilidad, la escrupulosidad y el tesón, entre otras. Estas tendencias interactúan con la cultura para dar lugar a las características adaptativas, entendidas estas como el conjunto de actitudes, valores y creencias que presentan los individuos, así como también su autoconcepto y autoestima. Todo ello circula en contacto directo con las influencias del contexto histórico-cultural y social del individuo, a través de un proceso dinámico de movimiento permanente.

Para Piedmont, se hace fundamental estudiar la religiosidad y en un plano más amplio, la espiritualidad, como una dimensión que se va configurando en el individuo a lo largo del ciclo vital y cumple una función adaptativa y a su vez de trascendencia. La religiosidad en cuanto sistema de creencias, prácticas y valores explícitamente pautados e inmersos en determinadas tradiciones sociales o marcos institucionales, depende directamente de la educación y la cultura y en modo alguno deriva de una entidad inmanente.

Esta teoría de los cinco factores rescata la religiosidad de una noción meramente abstracta y la extrapola al campo concreto del sujeto, ubicándolo como rasgo de la personalidad y tendencia básica del estatuto de humanidad, lo cual posibilita su abordaje metodológico a partir de la exploración de los imaginarios que se han construido en torno a ella, pues lo que constituye un imaginario social sobre religiosidad, es, igualmente, lo que define dicha cualidad.

\section{Eclecticismo metodológico aplicado a los imaginarios en torno a la ciudadanía y la religiosidad}

Abordando de manera específica el interés ya descrito del presente artículo, orientado a evidenciar las contribuciones epistemológicas respecto de la categoría imaginarios, enfatizando un aspecto especifico de la vida social referido a la comprensión de las relaciones entre religiosidad y ciudadanía, empezaremos por precisar que los imaginarios operan como matrices de sentido a través de las cuales los sujetos configuran su realidad social y en consecuencia, son necesarios para develar la vida particular y la pluralidad de la vida social. Tal como lo propone Maffesoli (1993), develar esta pluralidad implica un acercamiento desde la polifonía de la vida, que equivale a decir muldimensionalidad de intervenciones (económicas, políticas, culturales, administrativas y cotidianas) que constituyen la cotidianidad en la que se inscriben los sujetos. Por ello, cada momento histórico y contexto cultural delineará el propio paisaje de la realidad social para el sujeto. La pretensión de universalizar y homogenizar será una tarea baldía, y la exigencia de aprehender la totalidad de la realidad será una empresa imposible.

En consecuencia, los imaginarios sociales son artificios conceptuales que nos permitirán, desde una perspectiva del pluralismo metodológico, adentrarnos en el único universo desde el cual se origina la validez, el sujeto como vida particular. Ello requiere tomar partido por un método cualitativista, en el que se concede relevancia al simbolismo que da cuenta del orden instituido y el orden instituyente.

En este orden de ideas se retoma el interés del presente artículo de abordar la reflexión epistemológica de los imaginarios, enfatizada sobre un aspecto de la vida particular representado en la religiosidad, ubicándola desde sus fuentes primigenias, como orden instituyente que dota de sentido a los sujetos. Para comprender la religiosidad desde esta 
perspectiva, es necesario relacionarla como mythos, y el papel que este ha desempeñado en las sociedades: "El mito tiene -o ha tenido hasta estos últimos tiempos- 'vida', en el sentido de proporcionar modelos a la conducta humana y conferir por eso mismo significación y valor a la existencia” (Eliade, 1985, p. 5). Desde este punto de partida, se pueden rastrear los arquetipos del imaginario de los que habla Durand (1992), asumiendo dicho imaginario como corpus simbólico que supone la adhesión a un sistema de valores capaz de moldear conductas y movilizar las energías del colectivo social hacia una acción común:

Una organización dada de la economía, un sistema de derecho, un poder instituido, una religión, existen socialmente como sistemas socialmente sancionados. Consiste en ligar a símbolos (a significantes) unos significados (representaciones, órdenes, conminaciones o incitaciones a hacer o a no hacer, unas consecuencias, unas significaciones, en el sentido lato del término) y en hacerlos valer como tales, es decir, hacer este vehículo más o menos forzado para la sociedad o grupo considerado. (Castoriadis, 1988, p. 187)

El desafío metodológico no radica en describir el imaginario en su contenido. Justamente, se trata de identificar de dónde emerge y cómo llega a convertirse en portador de sentido, y mejor aún, cómo determina las prácticas (Hiernaux, 2007). En este orden de ideas, se requiere "un modo constitutivo de preguntar, desde donde se debe interpretar, en la cotidianidad" (Hurtado, 2007). Unido a lo anterior, se requiere develar la trama histórica que lo presentiza:

El mundo del sentido trasmitido se abre al intérprete solo en la medida en que se aclara a la vez el propio mundo de este. El que comprende mantiene una comunicación entre los dos mundos; capta el contenido objetivo de lo trasmitido por la tradición y a la vez aplica la tradición a sí mismo y a su situación. (Habermas, 1998, p. 171)

Queda claro que, bajo el pluralismo metodológico, los imaginarios sociales pueden ser objetos estudiados desde un enfoque hermenéutico, en cuanto esta mirada comprensiva permite recuperar las vidas particulares y comprender el sentido que tienen en ellas, las prácticas colectivas. Es decir, se trata de relevar "la importancia de la explicación comprensiva para establecer los sentidos, las motivaciones y los propósitos de las acciones de los agentes" (Vasco, 1994, p. 20). Es decir, en el análisis de los imaginarios como categoría bisagra, se logra identificar la relación entre el actor y el mundo, y de ella la construcción de sus realidades como procesos dinámicos y no como estructuras estáticas. Ahora bien, es necesario asumir una perspectiva reflexiva sobre los imaginarios que nos lleve a prácticas sensitivo-investigativas, de tal forma que logremos aproximarnos a sus rasgos sociales y profundizar en la organización cultural de cada colectivo. Estas ideas proporcionan un hilo conductor clave que señala las razones de por qué se escoge un método centrado en los imaginarios sociales, desde una mirada cualitativista que da la posibilidad de comprender las vidas particulares y su devenir. Este es un asunto relevante para esta investigación, pues más que buscar regularidades que emergen de un orden prescriptivo, interesa identificar e interpretar los imaginarios que dan cuenta de las circulaciones y disrupciones entre religiosidad y ciudadanía.

Si se asume que el enfoque cualitativo es "un proceso cuestionador de comprensión, basado en distintas tradiciones metodológicas que exploran problemas sociales humanos" (Creswell, s.f., p. 15), así como sus experiencias, comportamientos, emociones y sentimientos, se concluye que un diseño metodológico afín a estas búsquedas puede encontrarse en la microetnografía, la cual hace alusión tanto a una forma de actuar en la investigación de campo como al producto que se espera obtener de la actividad investigativa. El diseño microetnográfico se centra en el análisis detallado del registro de la interacción que se da en eventos microlocalizados de cualquier tipo de realidad social. En gran parte de este tipo de diseño metodológico, se intenta reconstruir el código o 
la competencia comunicativa que rige y genera la interacción verbal y no verbal de los actores. Estos códigos o competencias varían de contexto a contexto, de cultura a cultura, según diferentes pautas de socialización y es la práctica microetnográfica una recopilación de descripciones detalladas de situaciones localizadas, eventos, personas, interacciones y comportamientos observables dentro de ellas, para luego ser reinterpretados a la luz de nuevas gramáticas.

Esta perspectiva contribuye, a partir de la sistematización de información diversa (conversaciones, imágenes, diálogos colectivos, relatos, autobiografías, etc.), a describir la forma como adquieren los imaginarios a partir de este acervo, convirtiéndose de esta manera en mensajeros de estos sentidos ocultos de ciudadanía y religiosidad y de sus posibles entramados.

\section{Reflexiones finales}

Los argumentos planteados en el artículo dejan en evidencia que los imaginarios no pueden ser definidos de una manera precisa, como se pretende en las ciencias sociales de corte analítico. Es fundamental, por lo tanto, una postura epistemológica que dé fuerza a otros sistemas de racionamiento científico que se empeñen en afrontar y densificar la complejidad de los fenómenos sociales. En este orden de ideas, se resalta que más que buscar significados, interesa develar los sentidos encarnados en dichos imaginarios. Es decir, desentrańar los ejes de sentido implicados en los imaginarios entramados de ciudadanía/religiosidad, obliga a emprender una tarea de artesano apasionado, de critico que sospecha, de narrador que sabe que su relato es interpretación de segundo orden, porque no es posible aprehender la realidad social más que como una narración saturada de sentidos inscritos en la cultura. Como lo expresa Cegarra (2012): "Los imaginarios constituyen un repertorio de sentidos que se han legitimado en un marco social y cultural para interpretar comportamientos sociales y legitimar determinadas valoraciones ideológicas y culturales". (p. 13)

En suma, el intento de responder a la pregunta de por qué los imaginarios pueden ser una categoría analítica para los estudios en las ciencias sociales y específicamente para dar cuenta de las tramas de sentido construidas entre religiosidad y ciudadanía, deja en claro que estos tramitan arquetipos de sentido de la religiosidad hacia la ciudadanía y desde la ciudadanía hacia la religiosidad, posibilitando de esta manera la emergencia de los significantes instituyentes que determinan las prácticas del sujeto político.

Elaboradas y modificadas por la historia, las matrices de sentido que traman estas dos dimensiones favorecen la cohesión y la identidad sociales y son claves a la hora de comprender qué tipo de ciudadanía está emergiendo en medio de estas creaciones simbólicas derivadas de la religiosidad en jóvenes. Ahora bien, es importante ahondar en el papel que están jugando los bancos de sentido como la familia, la escuela, la religión y los medios de comunicación en esta configuración, y la forma como los reservorios materiales disponibles socialmente como discursos, imágenes, actitudes, valoraciones y prescripciones, están corporizando, necesariamente, el orden instituido, mostrando las fisuras y líneas de fuga que está liberando el instituyente. Es decir, la esencia de lo que no ha sido y se está creando.

Finalmente, los imaginarios sociales contienen una extensa tematización a partir de autores tan potentes como Castoriadis, Durand, Carretero, Baeza y Pinto, todos ellos, con diferencias en sus marcos de interpretación, coinciden en el interés por dar cuenta de la vida particular atravesada por la cultura. Nuestra tarea apenas empieza. Rastreamos en la cultura las pistas de las múltiples matrices de poder, cuyas intersecciones entre 
religiosidad y ciudadanía aún no han sido desapasionadamente develadas. La sociedad humana ha pasado siglos separando la vida religiosa de la vida política y esa conquista en modo alguno trata de ignorarse con estas búsquedas. Sin embargo, intuimos que a partir de los imaginarios tomados como categoría bisagra, podemos rastrear en la cultura las intersecciones entre religiosidad y ciudadanía, dando cuenta así de la configuración de un sustrato ético desde el cual se potentiza el sentido de una ciudadanía republicana al estilo arendtiano, a partir del cual se crean órdenes en función de una mejor vida en comunidad.

\section{Referencias}

Abric, J. (2001). Metodología de recolección de las representaciones sociales. Prácticas sociales y representaciones. Mexico: Ediciones Coyoacán, S. A. de C. V.

Arendt, H. (2001). ¿Qué es la política? Barcelona: Paidós.

Argüello, S. (2012). La lectura romana y la evolución de la enseñanza de Tomás de Aquino sobre la imagen y semejanza de Dios. Revista Estudios Filosoficos. LXI; 177;9-2012;245-276. Argentina: Editorial San Esteban.

Baeza, M. (2008). Ocho argumentos básicos para la construccion de una teoria fenomenológica de los imaginarios sociales. Revista de Ciencias Sociales y Humanidades, núm. 64-65, pp. 311315. Chile: Universidad de Concepcion

Caerols, J. (ed.). (2013) Religio in labyrintho. Encuentros y desencuentros de religiones en sociedades complejas. Madrid: Escolar y Mayo editores

Carracedo, J. R. (2007). Teoría crítica a de la ciudadanía democrática. Madrid: Trotta.

Carretero, A. (2001). Imaginarios sociales y crítica ideológica. Una perspectiva para la comprension de la legitimacion del orden social. Recuperado de https://biblioteca.org.ar/libros/140080.pdf

Castoriadis, C. (1988). Los dominios del hombre. Las encrucijadas del laberinto. Barcelona: Gedisa

Castoriadis, C. (1989). La institución imaginaria de la sociedad. Barcelona: Tusquets.

Castoriadis, C. (1997). El imaginario social instituyente. Zona Erógena. № 35. Recuperado de: http://www.ubiobio.cl/miweb/webfile/media/267/Castoriadis\%20Cornelius\%20-\%20El\%20 Imaginario\%20Social\%20Instituyente.pdf

Castoriadis, C. (2004). Sujeto y verdad en el mundo histórico social. México: Fondo de Cultura Económica.

Cegarra, J. (2012). Fundamentos teóricos epistemológicos de los imaginarios sociales. Recuperado de https://doi.org/10.4067/S0717-554X2012000100001

Creswell, J. (s.f.). Qualitative inquiry and research design. Documento en proceso de construcción. Traducción del libro original en inglés producto de la línea de investigación en juventud, del doctorado en Ciencias Sociales Niñez y Juventud. Recuperado de: http://academia.utp.edu.co/ seminario-investigacion-II/files/2017/08/INVESTIGACION-CUALITATIVACreswell.pdf

Durand, G. (1992). Les structures anthropologiques de l'imaginaire. París: Dunod.

Durkheim, E. (1964). The Elementary Forms of the Religious Life. London: George Alien \& Unwin.

Eliade, M. (1985). El mito del eterno retorno. México: Planeta-Agostini.

Ferrater, Mora. (1992). Diccionario de filosofía. Barcelona: Círculo de Lectores

Habermas, J. (1998). Facticidad y validez. Madrid: Trotta.

Hiernaux, D. (2007). Los imaginarios urbanos: de la teoría y los aterrizajes en los estudios urbanos. Revista Eure (Vol. XXXIII, No 99), pp. 17-30, agosto de 2007. Recuperado de: https://scielo. conicyt.cl/pdf/eure/v33n99/art03.pdf

Hurtado, D. (2007). La configuración de imaginarios de deseo en jóvenes. Manizales: [Tesis doctoral]. Recuperado de: http://ridum.umanizales.edu.co:8080/xmlui/bitstream/handle/6789/602/501_Hurtado_Herrera_Deibar_Rene\%20file1.pdf?sequence=4\&isAllowed=y 
Lozano, M. (2009). La política, la democracia y la ciudadanía en los juicios, discursos y acción política en grupos de jóvenes estudiantes universitarios de Bogotá. [Tesis doctoral]. Recuperado de: http://bibliotecavirtual.clacso.org.ar/Colombia/alianza-cinde-umz/20091215035655/ TESISMARTHACLOZANO.pdf

Maffesoli, M. (1993). El conocimiento ordinario. Compendio de sociología. México: Fondo de Cultura Económica.

Miranda, R. (2008). Castoriadis y el regreso de lo religioso: Autoalteración de la sociedad y metanorma. Recuperado de http://www.scielo.org.mx/scielo.php?script=sci_arttext\&pid=S1665$80272008000100008 \& \operatorname{lng}=e s \&$ tlng=es.

Osorio, F. (2017). Epistemología de las ciencias sociales. Chile: Ediciones Universilibros

Paya, V. Juárez, A., et al. (2005). Institución, imaginarios y socioanálisis. Mexico: Facultad de estudios superiores de Acatlan. Recuperado de: https://www.worldcat.org/title/institucion-imaginarioy-socioanalisis/oclc/133172175

Piedmont, R. (2013). Spirituality, religiousness, and personality. Washington DC: American: Psychological Association.

Pintos, J. (1995). Los imaginarios Sociales. La nueva construcción de la realidad social. Cantabria, Madrid, España: Sal Terrae/ "Fe y Secularidad".

Reynoso, C. (2000). Apogeo y decadencia de los estudios culturales: Una visión antropológica. México: Gedisa

Simon, V. ( 2002). Las trampas de la imaginacion. Psicothema 14(3): 643-650.

Taylor, Charles. (2006) Imaginarios sociales modernos. México: Paidós

Tellkamp, J. (1996). Teoría de la percepción de Tomás de Aquino. Revista Universitas Philosophica, $45-67$

Tuggy, A. (2003). Léxico griego español del Nuevo Testamento. Editorial Mundo Hispano

Ugas, F. G. (2007). Epistemología de la educación pedagogía. San Cristobal Tachira Venezuela: Taller permanente de estudios epistemológicos.

Uribarri, F. (2000). Castoriadis: la sublimación extendida. Revista Zona Erógena, 45, 53-58.

Uribe, M. (2013). Esfera pública acción política y ciudadanía. Una mirada desde Hannah Arendt. Estudios Políticos (10), 165-184. Recuperado de: https://dialnet.unirioja.es/servlet/ articulo? codigo $=5263619$

Vasco, C. (1994). Tres estilos de trabajo en las Ciencias Sociales . Buenos Aires: Noveduc.

Weber, M. (1964). Sociología de la religión. Buenos Aires: Editorial La Pléyade.

Zolla, E. (1968). Historia de la imaginación viciosa: ensayos. Monte Ávila Editores. 